\title{
Effect of Mg additions, Hot-Extrusion and Cold-Rolling on Microstructure and Mechanical Properties of 2024 Alloy during Aging
}

\author{
C.G. Garay-Reyes ${ }^{1}$, A. Hernández-Arrollo ${ }^{2}$, I. Estrada-Guel ${ }^{1}$, H. M. Medrano-Prieto ${ }^{1}$, J. M. Mendoza-
} Duarte $^{1}$, M. C. Maldonado-Orozco ${ }^{2}$, and R. Martínez-Sánchez ${ }^{1}$

${ }^{1}$ Centro de Investigación en Materiales Avanzados (CIMAV), Laboratorio Nacional de Nanotecnología, Miguel de Cervantes No. 120, 31136, Chihuahua, Chih., México.

${ }^{2}$ Universidad Autónoma de Chihuahua (UACH), Facultad de Ingeniería, Circuito No. 1, Nuevo Campus Universitario, CP 31125 Chihuahua, Chih., México.

Al alloys of 2xxx series (2024) with high specific strength, good fracture toughness, and excellent fatigue properties have been found important applications in the aerospace industry. In commercial 2024 alloys, $\mathrm{Cu}$ and $\mathrm{Mg}$ are the main alloying elements with small amount of $\mathrm{Si}$ and other minor elements such as $\mathrm{Mn}, \mathrm{Zn}$, Ti and Fe. Nonetheless, has recently been reported an increment on strength and hardness by $\mathrm{Mg}$ addition (<2 wt. \%); however, this is accompanied by a decrease in ductility and impact resistance [1]. In this work is evaluated the effect of hot-extrusion and cold-rolling on microstructure and hardening of the 2024 alloy modified with magnesium during aging heat treatment.

The 2024 alloy fabrication with $\mathrm{Mg}$ additions ( $0.25 \mathrm{wt}$. \%) was made by conventional direct casting, the melt was degassed with argon gas $(20 \mathrm{psi})$ for $5 \mathrm{~min}$ period and AlTiB was added as grain refiner $(0.13$ $\%$ wt.). Modification with $\mathrm{Mg}$ was performed with addition of pure $\mathrm{Mg}(99.99 \%)$. The hot-extrusion (HE) consisted of a thickness reduction in the samples $(10 \mathrm{~mm}$ in diameter) by using indirect extrusion and an extrusion ratio of 16 at $480{ }^{\circ} \mathrm{C}$. The solution heat treatment (SHT) was at $495^{\circ} \mathrm{C}$ for $7 \mathrm{~h}$. The coldrolling (CR) involved 5 to $15 \%$ thickness reductions; and a final aging step $\left(195^{\circ} \mathrm{C}\right)$ at several times was realized. The microstructural characterization was done using an optical microscope (OM) ZEISS model Scope A1, a SEM Hitachi model SU3500 and a TEM PHILIPS model CM-200; XRD analyses were performed in a Panalytical X'Pert PRO diffractometer. The mechanical properties were evaluated using hardness test in a LECO LM300AT microhardness tester in accordance with the ASTM standards.

The Fig. 1 shows the HE and SHT effects on microstructure of 2024 (Mg) alloy. The microstructure changed of dendritic grains in as-cast condition to equiaxed grains after HE. The spatial distribution of $\mathrm{Cu}$-rich phases becomes more homogeneous and smaller particles are observed. In addition, after SHT dissolution of $\mathrm{Cu}$-rich phases was carried out. The Fig. 2 shows a) age-hardening curves of 2024 (Mg and 2024 (Mg) HE alloys after of CR 5 and $15 \%$; b-c) shows XRD graphs of 2024 and 2024 HE alloys in conditions as cast, as cast+ HE, SHT and at the maximum peak during aging.

For Fig. 2a, it is evident highest hardness value in samples after CR 15\% just after plastic deformation associated to dynamic precipitation and a second peak at $600 \mathrm{~min}$ aging associated to $\mathrm{Al}_{2} \mathrm{Cu}$ and $\mathrm{Al}_{2} \mathrm{CuMg}$ precipitates. For Figs. 2b-c, it is evident the formation of $\mathrm{Al}_{2} \mathrm{Cu}$ and $\mathrm{Al}_{2} \mathrm{CuMg}_{\mathrm{M}}$ precipitates, which are responsible of second peak hardening. It is concluded that the HE and $\mathrm{CR}$ generate changes microstructural that improve the hardness of 2024 alloy and a double peak hardening due dynamic precipitation.

References:

[1] C.G. Garay-Reyes, I. K Gómez-Barraza, M. A. Ruiz-Esparza-Rodríguez, I. Estrada-Guel, J. P Flores-De los Ríos, M. C. Maldonado-Orozco and R. Martínez-Sánchez, Microsc. Microanal. 23 (Suppl 1) (2017) p. 400-401. 


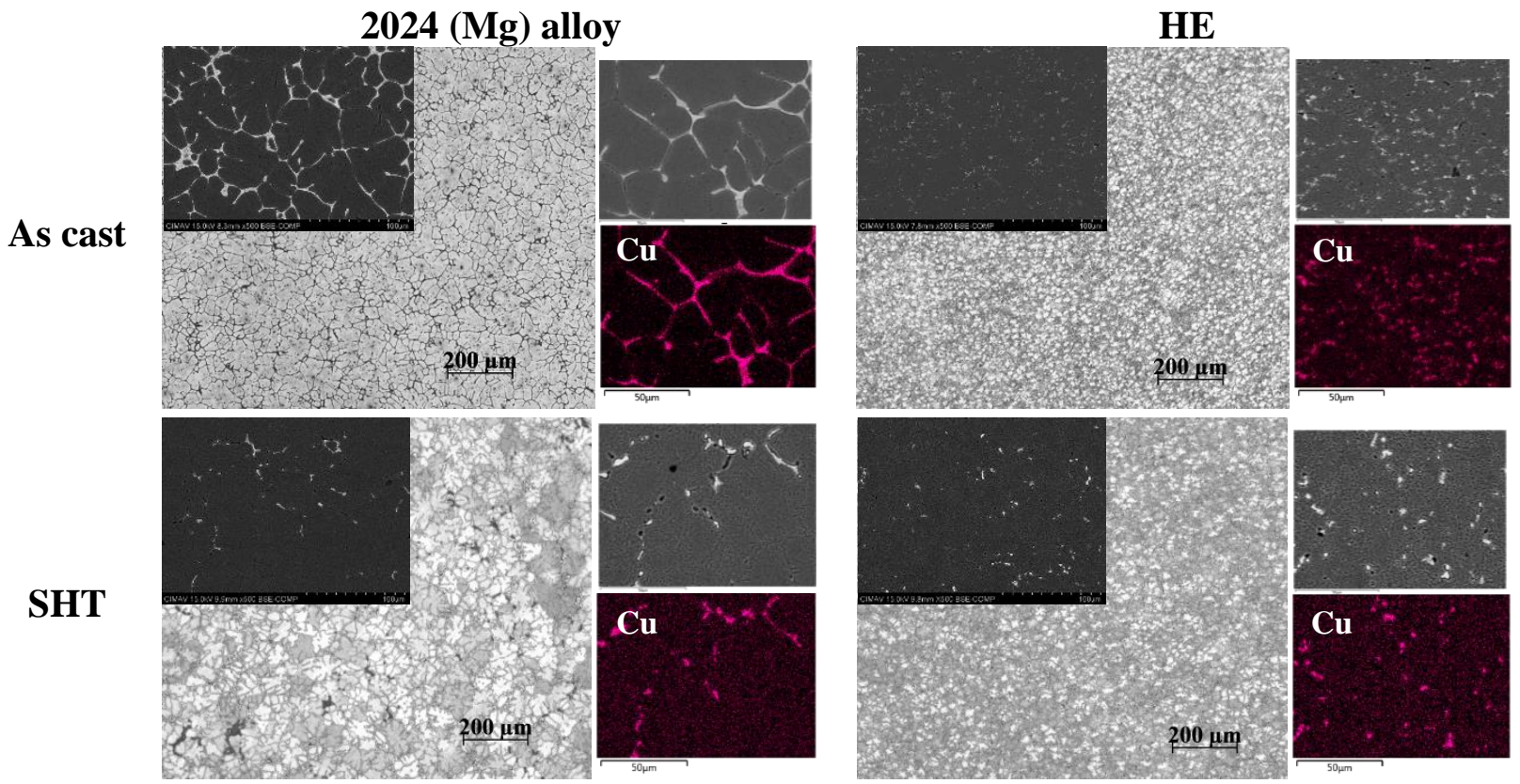

Figure 1. OM-SEM-Maps Micrographs of 2024 and $2024 \mathrm{HE}$ alloys in as cast condition and SHT.
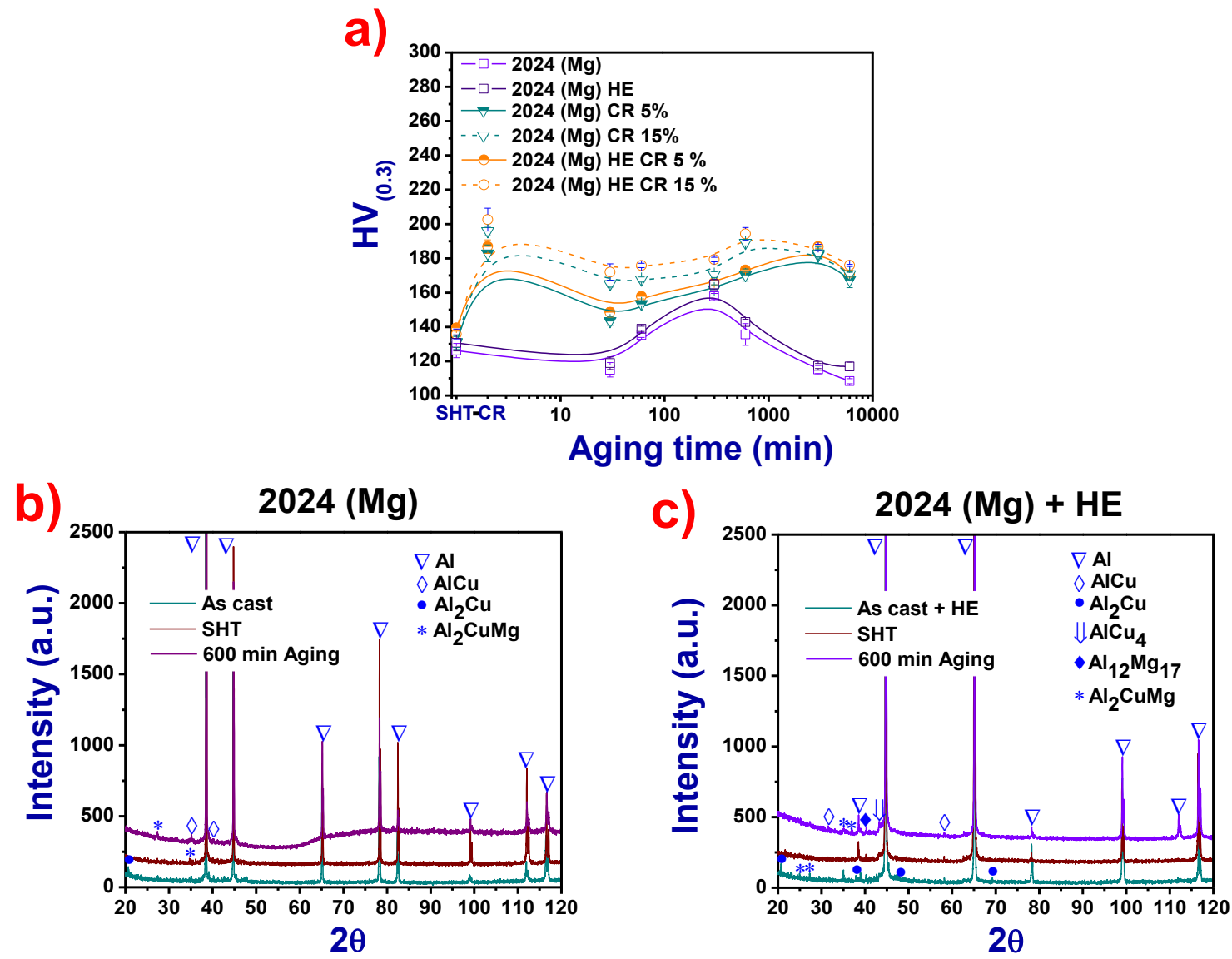

Figure 2. a) Graph of the Vickers hardness (HV) versus ageing time and b-c) XRD graph. For 2024 and $2024 \mathrm{HE}$ alloys, in conditions as cast, as cast+ HE, SHT and peak aging. 